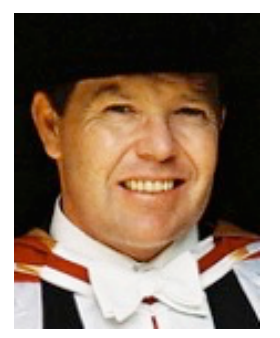

Mark L Shepheard

University of New England

Australia

\title{
INDIGENOUS KNOWLEDGE STEWARDSHIP AND ACCOUNTABILITY OF SEED BANK INSTITUTIONS
}

\begin{abstract}
A growing emphasis among seed banks in Australia and globally is the collection of seed and information associated with wild crop relatives of food and fodder crops. This is part of scientific efforts to store and document plant traits that may prove useful to deal with risks to food and bio security in the face of global climate changes. This has implications for indigenous communities because of the risk that indigenous knowledge may be collected and included as 'data' rather than as knowledge with significant cultural tethering. This articl provides a theoretical context for institutional seed banks to engage with indigenous people and specify indigenous knowledge stewardship accountability. This should help seed banks to operate with sensitivity to cultural wellbeing and minimise the risks from failure to satisfy accountability for indigenous knowledge stewardship. The article identifies four interrelated dimensions of indigenous knowledge stewardship, and identifies a tentative process for institutions to adapt this to indigenous knowledge stewardship strategy and practice. The process for realising indigenous knowledge stewardship accountability is the subject of further research.
\end{abstract}

\section{Introduction}

This article focusses on the need for greater protection of indigenous knowledge in the operations and collection-management practice of seed banks. It outlines a theoretical framework for improving strategy and practice in seed bank institutions to ensure stronger protection of indigenous knowledge through stewardship. This is based on institutional adoption of cultural wellbeing and risk management in the context of international legal standards for consent and use of plant resources; and to the transfer of indigenous knowledge with access and benefit sharing arrangements in place.

Conservation seed banks in Australia are typically contained in botanical institutions (such as botanical gardens and associated herbaria). They undertake national scale seed collecting, banking, research and knowledge sharing activities in order to safeguard Australia's native plant resources, including crop wild relatives and plants with economic potential. At the heart of the operation is an ex situ seed collection held within a network of seed bank facilities spread across the country. Ex situ conservation of seeds involves collection of samples and data, which must then be catalogued, stored and maintained for future access and use.

Developing indigenous knowledge stewardship of conservation seed banks requires seed and knowledge transactions relationships that are based on good practice to ensure indigenous knowledge and ecological wellbeing is not put at risk by seed bank operations. The term, indigenous knowledge stewardship, is used as shorthand to define a relationship between seed banks and indigenous communities that respects indigenous interests in seeds and emphasises the value of traditional knowledge. The importance of this relationship is realised when it is used as the basis for a process to define the boundaries of accountability for indigenous knowledge stewardship in seed bank systems.

Defining indigenous knowledge stewardship has three important functions for seed bank institutions:

1. To define boundaries of accountability;

2. To choose the conditions under which the institution will or will not accept accountability; and,

3. How to administer the related responsibility that accountability brings.

These are important practical concerns amid increasingly stringent rules that reinforce equity and benefit sharing associated with access to traditional knowledge; with increased use of ethical requirements to 
anticipate performance outcomes, and seed banks seeking increased access to indigenous lands to strengthen their collection of wild crop relatives.

For conservation seed banks to clearly identify and put indigenous knowledge stewardship into practice is a way to minimise the risks associated with seed bank operations and indigenous knowledge integrity. The first part of this article sets out the conceptual foundations for indigenous knowledge stewardship with cultural wellbeing and risk management, emphasising four interconnected dimensions of a relationship that fosters cultural wellbeing: norms of behaviour, alliance building, legitimacy and trust. Relationships of knowledge exchange that are structured on these dimensions provide a sound basis for institutional risk management that allows seed banks to address the accountability they bear for indigenous knowledge stewardship.

\section{Importance of indigenous knowledge stewardship to seed bank performance}

Managing the risks to seed banks effectively requires transactions at all stages of the collections management process to comply with indigenous knowledge stewardship responsibility. This means that there is respect for legitimate indigenous knowledge interests, and exchange and transactions are carried out with concern for equity.

Institutional use of codes or guides is encouraged to promote transacting relationships that comply with obligations. ${ }^{1}$ However, such codes alone are not adequate to lay the foundation for a mutual relationship of respect that is integral to recognising and achieving indigenous knowledge stewardship performance, which requires a structured approach for engagement with stakeholders and cooperative effort to identify the nature of relationships, the type of transactions, the associated risks, and capacity for seed bank collections management to incorporate indigenous knowledge stewardship.

Indigenous knowledge stewardship is conceived as a boundary of responsibility for seed bank relations with indigenous people. It is critical that this boundary includes legal obligations and establishes the basis for moral choices by seed bank staff that are likely to be consistent with indigenous community expectations about indigenous knowledge stewardship. Importantly, seed bank management must ultimately choose what level of accountability the institution will accept in maintaining indigenous knowledge stewardship.

\section{Conceptual foundations for indigenous knowledge stewardship accountability}

Defining the accountability of seed bank institutions for their indigenous knowledge stewardship is a complex task. It involves placing the exchange of seeds and indigenous knowledge about them in the context of a relationship between seed banks and indigenous people. Formation of this relationship and teasing out its impact on cultural wellbeing is ideally a prerequisite for exchange of seeds and knowledge. In this way, wellbeing provides a conceptual basis for defining the accountability a seed bank holds for its indigenous knowledge stewardship. This section begins with an overview of the nature and potential scope of indigenous knowledge about seeds, and how such knowledge is subject to expectations of accountability imposed on seed bank institutions. Being able to anticipate and manage the risks associated with expectations of accountability ought to be an important part of a seed bank's strategy and operations. In this way, cultural wellbeing provides a conceptual foundation for indigenous knowledge stewardship.

\section{A view about the scope and nature of indigenous knowledge}

Indigenous Australian's knowledge about their geographic country is an evolving accumulation of human innovation and ecological adaptation stretching across time. ${ }^{2}$ It is an experiential system, which is the product of observations across generations, about inter-relationships between people and place and the inherent moral responsibilities these connections bring. ${ }^{3}$ In this way the preservation of nature is

\footnotetext{
1 For example, Australian Institute of Aboriginal and Torres Strait Islander Studies, 'Guidelines for Ethical Research in Australian Indigenous Studies' (AIATSIS, 2010) <www.aiatsis.gov.au/_files/research/ethics.pdf>.

2 Justin M Nolan and Nancy J Turner, 'Ethnobotany: The Study of People-Plant Relationships', in E N Anderson et al (eds), Ethnobiology (Hoboken, Wiley-Blackwell, 2011).

${ }^{3}$ Laurelyn Whitt, Science, Colonialism, and Indigenous Peoples. The Indigenous Knowledge Politics of Law and Knowledge (Cambridge University Press, 2009).
} 
fundamental, since life, culture and spirituality are all linked to country. ${ }^{4}$ Broadly, indigenous knowledge systems are cross-gerational and not independent of products, expressions or actions, and include: ${ }^{5}$

1. Communal rights and interests;

2. Interdependence between knowledge, land and spirituality;

3. Oral transmission in accordance with customary rules and principles;

4. Sacred and secret knowledge management rules; and

5. Sacred and secular dimensions are equally valid.

By nature, these knowledge systems combine the social, cultural, and biophysical details (such as those listed above) as a communal yet individually interpreted way of knowing about survival in a particular place. ${ }^{6}$ The systems pull history, knowledge, religion and morality together as an important part of capacity to care for country. ${ }^{7}$ The bond between people and place has been identified as a type of fiduciary relationship. ${ }^{8}$ This helps emphasise that biodiversity conservation and protection of the environment as a whole cannot be isolated from indigenous knowledge construction. ${ }^{9}$ People in this sense exist inside an ecological system; they are holders of country and are held by country. ${ }^{10}$

\section{Indigenous knowledge stewardship and wellbeing}

Indigenous knowledge stewardship is primarily about building better relationships with indigenous people surrounding the collection, storage, management and use of seeds and associated knowledge. This is a form of unwritten consent reflecting expectations of a community. This accountability anticipates performance that contributes to wellbeing and capacity in local communities ${ }^{11}$ without necessarily having a clear definition about what this means. Such relationships are potentially conceptualised as based upon respect for legitimacy of indigenous knowledge where wellbeing may serve as a reference point in the transacting relationship for indigenous knowledge stewardship accountability. ${ }^{12}$ Wellbeing, in this sense, may reflect notions that pull history, knowledge, religion and morality together in caring for country and understanding connections between people, place and products. ${ }^{13}$ This sense of connection and wellbeing is fundamental to appreciating indigenous knowledge stewardship concerns. Operationally for seed banks, this means building partnerships that recognise the social and ecological foundations of indigenous knowledge that are underpinned by trust and confidence.

Respect for cultural wellbeing may help seed banks to meet indigenous knowledge stewardship accountability by providing a focus for collections management strategy and practice. Effectively fostering and managing such relationships must be the product of a strategic process to define suitable boundaries of accountability and focus attention where obligations truly lie. Performance management in this context is more likely to result in efficient, effective and fair outcomes. ${ }^{14}$

\footnotetext{
4 John Scott, 'Protecting Traditional Knowledge and the Convention on Biological Diversity' (2006) 6(20) Indigenous Law Bulletin.

5 Michael Davis, 'Indigenous Rights in Traditional Knowledge and Biological Diversity: Approaches to Protection' (1999) 4(4) Australian Indigenous Law Reports 1, 5.

6 Robyn Bartel, 'Vernacular Knowledge and Environmental Law: Cause and Cure for Regulatory Failure' (2014) 19(8) Local Environment 891.

7 Lee Godden and Jacqueline Peel, Environmental Law: Scientific, Policy and Regulatory Dimensions (Oxford University Press, 2010) 37.

8 Laurelyn Whitt, Science, Colonialism, and Indigenous Peoples: The Indigenous Knowledge Politics of Law and Knowledge (Oxford University Press, 2009).

9 Libby Robin, Defending the Little Desert (Melbourne University Press, 1998) 3.

${ }^{10}$ Fiona Walsh, Peter Christopherson and Sandra McGregor, 'Indigenous Perspectives on Biodiversity' in Steve Morton, Andy Sheppard and Mark Lonsdale (eds), Biodiversity (CSIRO Publishing, 2014).

${ }^{11}$ Mark Fenton, 'Socio-Economic Indicators and Protocols for the National Natural Resource Management Monitoring and Wvaluation Dramework: Social and Institutional Doundations of Natural Eesource Management' (National Land and Water Resources Audit, 2006).

${ }^{12} \mathrm{H}$ A Reiger, 'The Notion of Natural and Indigenous Knowledge Integrity' in S Woodley, J Francis and J Kay (eds) Ecological Integrity and the Management of Ecosystems (St Lucie Press, 1993).

${ }^{13}$ Godden and Peel, above $n 7$.

${ }^{14}$ Paul Martin and Neil Gunningham, 'Leading Reform of Natural Resource Management Law: Core Principles', Environment and Planning Law Journal, 28 (2011)137.
} 


\section{Indigenous knowledge stewardship and accountability}

Given the warning: 'it is naïve in the context of complex organisations to put one's trust exclusively in the force of moral arguments and good intentions', ${ }^{15}$ it is worth examining the moral and ethical dimensions of seed bank institutional performance, and the weight of moral arguments and good intentions relative to indigenous knowledge stewardship accountability. This includes the role of moral and ethical concepts in forming notions of accountability in seed bank institutions.

Transactions surrounding indigenous knowledge stewardship are founded on relationships between people working for seed banks and members of an indigenous community. The relationships have two purposes: first, to establish the capacity of the institution as a worthy recipient of indigenous knowledge information; and second, to foster transactions that satisfy claims of justice and equity. ${ }^{16}$ These make transactions right from the view of both parties. But what is required for a seed bank to establish its capacity as a worthy recipient of indigenous knowledge information in a way that satisfies justice and equity?

Answering such a question demands analysis of how a seed bank institution establishes an organisational ethos that ensures its staff can demonstrate behaviour in transaction relationships to meet indigenous knowledge stewardship requirements. This recognises that the institution relies on the interpersonal, social and indigenous knowledge and the ethical context of transactions between people. ${ }^{17}$ Successful relationships require trust that the people involved will act to treat each other with respect. ${ }^{18}$ In this way, trust and respect are preconditions for establishing and maintaining transacting relationships. ${ }^{19}$ Placing greater emphasis on relationships with seed resource providers is likely to help provide a clear place for moral choices in seed bank operations. ${ }^{20}$ This emphasises operations that: reflect conviction for equality between people; can effectively transmit shared understandings in the institution to foster behavioural traits upon which successful transactions are founded; and have a fair and effective system of rules to coordinate that behaviour. ${ }^{21}$

Establishing these behavioural characteristics of performance is a matter of indigenous knowledge stewardship reputation for conservation seed banks. The challenge is to develop and enact responsible strategic and operational conduct that is prized in moral terms. ${ }^{22}$ This relies on seed banks developing a strategic approach to indigenous knowledge stewardship that puts moral choices into a transparent boundary setting process to minimise the risk that operations will be found wanting on indigenous knowledge grounds.

\section{Indigenous knowledge stewardship and risk management}

Developing accountability for performance in access and use of indigenous knowledge is consistent with broader natural resources performance management where social wellbeing and capacity are identified as important components in managing risk. ${ }^{23}$ This reflects the importance of developing enduring relationships: partnerships underpinned with trust and confidence as part of effectively connecting indigenous people with information sharing and knowledge exchange processes in seed bank institutions. . Having realtionships that facilitate input and access to institutional knowledge management systems by indigenous people is an important part of helping define responsible conduct of seed banks.

${ }^{15}$ Mark Bovins, The Quest for Responsibility, Accountability and Citizenship in Complex Organisations (Cambridge University Press, 1998).

${ }^{16}$ David Novak, 'Natural Law, Human Dignity and the Protection of Human Property' in Samuel Gregg and James Stoner (eds), Profit, Prudence and Virtue: Essays in Ethics, Business and Management (St Andrews Studies in Philosophy and Public Affairs, Imprint Academic, 2009).

${ }^{17}$ R Edward Freeman and David Newkirk, 'Business as a Human Enterprise' in Samuel Gregg and James Stoner (eds), Profit, Prudence and Virtue: Essays in Ethics, Business and Management (St Andrews Studies in Philosophy and Public Affairs, Imprint Academic, 2009).

${ }^{18}$ Robert P George, 'Business and Family in a Decent and Dynamic Society' in Samuel Gregg and James Stoner (eds), Profit, Prudence and Virtue: Essays in Ethics, Business and Management (St Andrews Studies in Philosophy and Public Affairs, Imprint Academic, 2009)

${ }^{19}$ Kevin T Jackson, 'Cultivating the Ethics-Economics Interface' in Samuel Gregg and James Stoner (eds), Profit, Prudence and Virtue: Essays in Ethics, Business and Management (St Andrews Studies in Philosphy and Public Affairs, Imprint Academic, 2009).

${ }^{20}$ Freeman and Newkirk, above n 17.

21 George, above n 18.

${ }^{22}$ Bovins, above $\mathrm{n} 15$.

${ }^{23}$ Mark Fenton, 'Socio-Economic Indicators and Protocols for the National Natural Resource Management Monitoring and Evaluation Framework: Social and Institutional Foundations of Natural Resource Management' (National Land and Water Resources Audit, 2006). 
Defining responsible conduct is about setting the boundaries of indigenous knowledge stewardship for which the seed bank is prepared to be accountable. ${ }^{24}$ Setting boundaries involves choosing the conditions under which the seed bank will or will not accept information, and how to administer the related responsibility. ${ }^{25}$ Setting boundaries provides an approach that minimises reliance on good intentions for defining the conduct of complex seed bank institutions. ${ }^{26}$ To make these choices in a prudent way requires that institutional staff operate in a system that is averse to the risks of indigenous knowledge stewardship and encourages proactive decision making about managing those risks. An effective process for establishing boundaries of accountability should help to ensure that indigenous knowledge stewardship is clear and integrated with the administrative choices made in seed banks.

Risk is a socially constructed concept and, therefore, based on what people know, understand and believe. The subjective and political nature of risk makes it a complex factor when defining the indigenous knowledge stewardship accountability of seed banks. ${ }^{27}$ Risk factors need to be carefully managed to ensure that the reputation of seed bank institutions remains intact for access to be maintained. Since risk is socially constructed, it must also be socially resolved. ${ }^{28}$ Social resolution requires that different interests and values are considered; and the threats to interests and values are carefully identified and evaluated relative to particular transactions. ${ }^{29}$ Identifying risk provides the opportunity to effectively implement accountability for indigenous knowledge stewardship.

There are several sources of possible risk to seed banks from the use of traditional knowledge associated with genetic resources. Stringent international obligations about traditional knowledge for plant genetic resources; a growing emphasis on social performance of scientific institutions; and global food security are illustrative as sources of indigenous knowledge stewardship risk. These are discussed below to highlight some of the issues that may be relevant to defining responsible conduct and offer compelling reasons for seed bank collections management systems to include indigenous knowledge stewardship:

1. Biological diversity is recognised internationally as an asset of great value to present and future generations. ${ }^{30}$ It is important for ecological and human wellbeing. ${ }^{31}$ This connection between ecological and human wellbeing has positioned the Convention on Biological Diversity ('CBD') as the preferred international forum for indigenous peoples to voice expectations about protection of their nature related interests. ${ }^{32}$ The $C B D^{33}$ has transitioned from the non-binding Bonn Guidelines (2002) ${ }^{34}$ to binding obligations under the Nagoya Protocol (2010). ${ }^{35}$ The Nagoya Protocol requires that benefits from the use of traditional knowledge about genetic resources in research and development are shared. This empowers benefit sharing as a means for indigenous communities to enforce equity in use of their traditional knowledge. ${ }^{36}$ Under these circumstances it is important for seed banks to have information storage and transmission systems in place to enable tracking links between genetic

\footnotetext{
${ }^{24}$ Mark Shepheard and Paul Martin, 'The State of Social Impact Indicators: Measurement without Meaning?' in Jacqueline Williams and Paul Martin (eds), Defending the Social Licence of Farming. Issues, Challenges and New Directions for Agriculture (CSIRO Publishing, 2011).

${ }^{25}$ Paul Martin and Michael Jeffery, 'Using a Legally Enforceable Knowledge Trust Doctrine to Fulfill the Moral Obligation to Protect Indigenous Secrets' (2007) 11(1) New Zealand Journal of Environmental Law.

${ }^{26}$ Bovins, above n 15, 216.

${ }^{27}$ Mark Shepheard, Mark Perry and Paul Martin, 'What do You Really Need to Know? An Overview of the Challanges Associated with the Management of Aboriginal and Torres Strait Islander Knowledge by Seed Bank Institutions' (CRC for Remote Economic Participation, 2014).

${ }^{28}$ Simon Gerrard, 'Environmental Risk Management' in Timothy O'Riordon (ed), Environmental Science for Environmental Management (Pearson Education Limited, 2000).

${ }^{29}$ Paul Martin and Jacqueline Williams, 'Policy Risk Assessment' (CRC for Irrigation Futures, 2010).

${ }^{30}$ Secretariat of the Convention on Biological Diversity, History of the Convention, Secretariat of the Convention on Biological Diversity <https://www.cbd.int/history/default.shtml>.

${ }^{31}$ Secretariat of the Convention on Biological Diversity, Sustaining the Earth: How the Convention on Biological Diversity promotes nature and human wellbeing (2000).

32 Elisa Morgera, Elsa Tsiomani and Matthias Buck, 'Unraveling the Nagoya Protocol: A Commentary on the Nagoya Protocol on Access and Benefit-Sharing to the Convention on Biological Diversirty' in Legal Studies on Access and Benefit-Sharing (Brill, 2014)

${ }^{33}$ CBD, art 1: 'fair and equitable sharing of the benefits arising out of the utilisation of genetic resources'. Terms and conditions of this are described in art 15.

${ }^{34}$ Secretariat of the Convention on Biological Diversity, 'Bonn Guidelines on Access to Genetic Resources and Fair and Equitable Sharing of the Benefits Arising out of their Utilization' (, 2002).

${ }^{35}$ Secretariat of the Convention on Biological Diversity, The Nagoya Protocol on Access and Benefit-Sharing and Traditional Knowledge <https://www.cbd.int/traditional/Protocol.shtml>

${ }^{36}$ Morgera, Tsioumani and Buck, above n 32.
} 
resources, traditional knowledge and its use as they move through collections management. This acknowledges the legitimacy of indigenous interests to share in the benefits of their knowledge. ${ }^{37}$

2. Knowledge about seeds is not the exclusive domain of expert scientific opinion. This means that botanical science cannot be considered adequate as the sole basis for decision-making in seed banks. ${ }^{38}$ Associated with this is greater potential for ethical principles to be used in assessment, management and appraisal of performance. ${ }^{39}$ Approvals that anticipate ethical performance reflect this trend. Seed bank transactions with indigenous communities can anticipate that rights, justice, fairness and precaution may be used to hold researchers and institutions to account for their activities associated with plant genetic resources. ${ }^{40}$

3. Global environmental change trends and associated food security concerns are a third source of risk to seed bank performance. Seed banks are promoting their value as insurance against potential biodiversity loss. As a result, Australian conservation seed banks are increasing their emphases on collection of wild crop relatives. There are a variety of crop wild relatives native to Australia, including species of: cow pea; citrus; yam; sweet potato; banana; rice; potato; tomato; sorghum; legumes; soybean; and cotton. ${ }^{41}$ These are potential sources of traits for disease resistance in cultivated varieties and are increasingly likely to be associated with collection from indigenous lands where they may be sourced with the aid of traditional knowledge. Governance arrangements surrounding access and use of wild crop relatives need to reflect indigenous knowledge stewardship concerns associated with use of traditional knowledge. Collections management that is proactive in the development of functional working relationships with indigenous peoples around access and use of genetic resources and knowledge are more likely to deliver on-going access. ${ }^{42}$

The risks associated with the issues above help to further place seed bank collections management in terms of honouring and upholding wellbeing in a relationship of trust with indigenous communities. ${ }^{43}$ Such moral choices $^{44}$ are to be acknowledged and acted on when seed banks further develop their collections management systems for indigenous knowledge stewardship. Performance here is compatible with the essential conditions of moral community, ${ }^{45}$ wellbeing and rights, ${ }^{46}$ which are the basis of a respectful relationship, and are important for risk management and realising responsible conduct. ${ }^{47}$

Risk management makes indigenous knowledge stewardship a potential issue of strategic importance to seed banks with increasing chance that seed banks are likely to be called to account for the risks and contingencies associated with indigenous knowledge stewardship in their collections management. But relationship building and accountability for indigenous knowledge is also likely to represent a significant challenge for seed bank institutions founded in botanical science and the exercise of an objective scientific method. Overcoming these challenges is important if seed banks are to adequately address possible sources of increased risk. The following section describes how interconnected dimensions of wellbeing can be understood as a process for defining boundaries of accountability for indigenous knowledge stewardship. The dimensions are identified and then a broad boundary setting process is described.

\footnotetext{
${ }^{37}$ Ibid 37.

${ }^{38}$ Karen Morrow, 'Genetically Modified Organisms and Risk' in Luc Bodiguel and Michael Cardwell (eds), The Regulation of Genetically Modified Organisms (Oxford University Press, 2010), DOI: 10.1111/cura.12066.

${ }^{39}$ Trudy R Turner, 'Large Scale Collections of Biological Material and Ethical First Principles' (2014) 57(2) Curator the Museum Journal 259.

${ }^{40}$ Morrow, above n 38.

${ }^{41}$ Peter Stoutjesdijk, 'Plant Genetic Resources for Food and Agriculture: Second National Report' (ABARES, 2013).

${ }^{42}$ Kate Davis, 'Biodiversity, Botanical Institutions and Benefit Sharing: Comments on the Impact of the Convention on Biological Diversity' in Charles McManis (ed), Biodiversity and the Law: Intellectual Property, Biotechnology and Traditional Knowledge (Earthscan, 2007) 72.

${ }^{43}$ ABS Capacity Development Initiative, 'Oceania Bidiscovery Forum Summary Report' (Australian Government and the Secretariat of the Pacific Regional Environment Programme, 2012).

${ }^{44}$ Mireille Hildebrandt and Antionette Rouvroy, Law, Human Agency, and Automatic Computing: The Philosophy of Law meets the Philosophy of Technology (Routledge, 2011).

${ }^{45}$ John Scott and Gordon Marshall, A Dictionary of Sociology (Oxford University Press, $3^{\text {rd }}$ ed, 2009): 'Moral Community Describes Typical Characteristics of Social Integration with Extensive and Intimate Attachments and Shared Beliefs About Morality and Behaviour'.

${ }^{46}$ L Westra, 'Environmental Rights and Human Rights: The final Enclosure Movement' in Roger Brownsword (ed), Human Rights: Global Governance and the Quest for Justice (HART, 2004).

${ }^{47}$ Neil Gunningham, 'Cotton, Health and Environment: A Case Study of Self-Regulation' (2004) 9(2) The Australasian Journal of Natural Resources Law and Policy 189.
} 


\section{Defining indigenous knowledge stewardship accountability}

Any organisation may draw on four interconnected dimensions of wellbeing to help define its indigenous knowledge stewardship accountability. These are: respect for cultural norms of behaviour; dialogue with community; developing legitimacy; and focus on developing exchanges based on trust. ${ }^{48}$ Table 1 describes these dimensions in greater detail.

Table 1. Theoretical dimensions of indigenous knowledge stewardship accountability

\begin{tabular}{|c|c|}
\hline Dimension & Description \\
\hline $\begin{array}{l}\text { Respect for } \\
\text { cultural norms } \\
\text { of behaviour }\end{array}$ & $\begin{array}{l}\text { Norms provide an important influence on the expectations of behaviour in any } \\
\text { industry. }{ }^{49} \text { Personal standards of behaviour; distinctions between right and wrong; } \\
\text { beliefs about what is valuable or important; and formal and informal rules of } \\
\text { conduct are all important considerations that give rise to expectations. Converting } \\
\text { these to practice requires some correlation between the norms, institutional culture } \\
\text { and operations. This is more likely when there is a mechanism to hold institutional } \\
\text { decision-makers accountable for performance against the norms. }\end{array}$ \\
\hline $\begin{array}{l}\text { Dialogue and } \\
\text { alliance } \\
\text { building }\end{array}$ & $\begin{array}{l}\text { Dialogue and alliance between interests requires relationships that are significant to } \\
\text { institutional performance. }{ }^{51} \text { Significance is based on power, legitimacy and urgency } \\
\text { with the ultimate effect of identifying to whom responsibility is owed. }{ }^{52} \text { Alliance } \\
\text { building requires awareness of joint interests and willingness to further those } \\
\text { interests through: dialogue, accepting that working together has its limits, that } \\
\text { relationships will not always be harmonious and that learning from each other is } \\
\text { essential. }{ }^{53}\end{array}$ \\
\hline Legitimacy & $\begin{array}{l}\text { Legitimacy arises from leadership and management; particularly when dialogue } \\
\text { between interests reflects a genuine intent. }{ }^{54} \text { Strategic leadership is important to } \\
\text { generate a conception of behaviour accountability that is evident throughout } \\
\text { institutional operations. }{ }^{55} \text { Legitimacy helps to ensure a focus on what is expected } \\
\text { rather than trying to address an open-ended range of socio-cultural, economic and } \\
\text { environmental issues. }\end{array}$ \\
\hline $\begin{array}{l}\text { Transacting } \\
\text { relationships } \\
\text { based on trust }\end{array}$ & $\begin{array}{l}\text { Trust between interests is a key consideration in maintenance of accountable } \\
\text { relationships. During resource access conflicts, partisan arguments are weighed in } \\
\text { the light of what is known about institutional performance and, therefore, whether } \\
\text { it is a trustworthy operator. Perceived failures of trust undermine credibility } \\
\text { relative to other interest groups. }\end{array}$ \\
\hline
\end{tabular}

Boundaries of accountability should be built on these dimensions and accurately reflect the indigenous knowledge stewardship a seed bank is prepared to be held accountable for and committed to act upon. Preparedness to act reflects the underlying values, indigenous knowledge norms and perceptions that exist

\footnotetext{
${ }^{48}$ Based on criteria identified in Mark L Shepheard and Paul Martin, 'Social Licence to Irrigate: The Boundary Problem' (2008) 27(3) Social Alternatives 32.

${ }^{49}$ Bridget M Hutter, 'The Role of Non-State Actors in Regulation' (London School of Economics and Political Science, 2006) 37.

50 Bovins, above n 15

${ }^{51}$ S Longstaff, Corporate Social Responsibility, St. James Ethics Centre <www.ethics.org.au>.

52 L Moir, 'What do we Mean by Corporate Social Responsibility?' (2001) 1(2) Corporate Governance 16; A B Carroll, 'The Pyramid of Corporate Social Responsibility: Toward the Moral Management of Organisational Stakeholders' (1991) 34(4) Business Horizons 39, doi.org/10.1108/EUM0000000005486.

${ }^{53}$ S Brooks, 'Corporate Social Responsibility and Strategic Management: The Prospects for Converging Discourses' (2005) 14 Strategic Change 401, DOI: 10.1002 /jsc. 731.

${ }^{54}$ M Muller and B Siebenhuner, 'Policy Instruments for Sustainability Oriented Organisational Learning' (2007) 16 Business Strategy and the Environment 232, DOI: 10.1002/bse.481.

${ }^{55}$ G P Lantos, 'The Boundaries of Strategic Corporate Social Responsibility' (2001) 18(7) Journal of Consumer Marketing 95, DOI: org/10.1108/07363760110410281; J Cramer, 'Company Learning About Corporate Social Responsibility' (2005) 14 Business Strategy and the Environment 255, DOI: 10.1002/bse.432; L Stainer, 'Performance Management and Corporate Social Responsibility: The Strategic Connection' (2006) 15 Strategic Change 253, DOI: 10.1002/jsc.761; ibid.
} 
about the organisation; the sense of its ethical obligations, operations and other considerations that may define its boundaries of accountability. ${ }^{56}$

Preparedness to act is likely to arise through awareness of community wellbeing concerns and through dialogue with the networks which link an organisation or institution to society. Wellbeing is described as an overall satisfaction with life and is recognised as a valuable concept in developing expectations of performance. ${ }^{57}$ Critical evaluation of the social and environmental performance of seed banks occurs through stakeholder networks, such as local indigenous communities. Networks are likely to be the 'place' where criticisms of seed banks acquire political power. As such, networks help foster shared norms and support cooperation that leads to changes in wellbeing. ${ }^{58}$

The importance of networks in fostering wellbeing suggests that boundaries of accountability may be best refined through a process where seed banks develop relationships with relevant communities, through which they explore their specific contribution to wellbeing through appropriate care of indigenous knowledge about plants. Attention to the welfare concerns of relevant networks makes it more likely that specific issues, circumstances and power relations will be reflected in a tacit agreement about responsibility. ${ }^{59}$ Such attention to welfare concerns may lead seed bank institutions to rate performance against contributions made to the wellbeing of specific networks rather than simply reporting poorly defined generalities about impacts. The following section outlines the process to help achieve responsible stewardship of indigenous knowledge within institutional seed banks.

\section{Defining indigenous knowledge stewardship using a boundary setting framework}

Successfully realising indigenous knowledge stewardship accountability fundamentally involves seed banks developing effective working relationships with indigenous people. Establishing such relationships requires an approach founded on the interconnected dimensions of indigenous knowledge stewardship accountability that are used to define a relationship founded on concern for cultural wellbeing and risk management. For a relationship to impact institutional accountability requires both strategy and performance management to define and put indigenous knowledge stewardship into practice. The improvement of institutional strategy and practice for indigenous knowledge stewardship is based on implementing concern for cultural wellbeing and risk management in the context of international legal standards of plant access and use. Implementing such concerns requires participation of internal and external interests in the development of publically acknowledged boundaries of accountability for indigenous knowledge stewardship.

The interests likely to be involved and specific processes for seed bank institutions to implement indigenous knowledge stewardship is the subject of further research. However the process is likely to have three broad steps (see Table 2).

Once accountabilities have been clarified (step 1, Table 2), genuine engagement with internal and external interests can help seed bank management to deepen their understanding of expectations and assist in refining the boundaries of indigenous knowledge stewardship accountability (step 2, Table 2). A seed bank institution can then examine the appropriate measures for demonstrating accountability and the internal processes required to achieve this (step 3, Table 2 ).

Following the three steps, a seed bank will be in a position to publically specify: its indigenous knowledge stewardship approach, the priorities for action, the issues and measures to be used in reporting, and the

56 John F Dovidio et al, The Social Psychology of Prosocial Behaviour (Lawrence Erlbaum Associates, 2006); Matthias Weber and Jens Hemmelskamp, Towards Environmental Innovation Systems (Springer, 2005); Michael Siegrist, Carmen Keller and Henk A L Kiers, 'A New Look at the Psychometric Paradigm of Perception of Hazards' (2005) 25(1) Risk Analysis 211; Francis Fukuyama, Trust (Penguin, 1995); Australian Bureau of Statistics, Measuring Wellbeing,

Frameworks for Australian Social Statistics (Australian Bureau of Statistics, 2001).

57 Longstaff, above n 51; Muller and Siebenhuner, above n 54; Franck L B Meijboom, Tatjana Visak and Frans W A Brom, 'From Trust to Trustworthiness: Why Information is not Enough in the Food Sector' (2006) 19 Journal of Agricultural and Environmental Ethics 427, DOI: 10.1007/s10806-006-9000-2; Australian Bureau of Statistics, 'Measuring Social Capital, an Australian Framework and Indicators' (Australian Bureau of Statistics, 1378.0, 2004).

58 Stewart Lockie et al, 'Capacity for Change, Testing a Model for the Inclusion of Social Indicators in Australia's National Land and Water Resources Audit' (2002) 45(6) Journal of Environmental Planning and Management 813, DOI: $10.1080 / 0964056022000024352$.

${ }^{59}$ Centre for Educational Research and Innovation, 'The Wellbeing of Nations: The Role of Human and Social Capital, Education and Skills' (OECD, 2001); Centre for Educational Research and Innovation, 'The Wellbeing of Nations: The Role of Human and Social Capital, Education and Skills' (OECD, 2001). 
internal systems to be used to satisfy the accountability requirements. Specification constitutes a statement of indigenous stewardship accountability that should be subject to periodic review and feedback, and forms the basis for a formal institutional strategy for indigenous knowledge stewardship to be publically reflected in performance reporting. The strategy, as reviewed over time, should remain a foundation for reporting the indigenous stewardship accountability of the institution.

Table 2. Three steps to identify indigenous knowledge stewardship accountability in seed banks

Step

1. Identify priority issues and justification for investment, monitoring and action

\section{Content}

a) Impacts expected to emerge as accountabilities over the next five to ten years, and their likelihood;

b) Actual impacts of the seed bank or anticipated impacts, the potential to ameliorate harm, and strategies for this; and.

c) Opportunity to make a meaningful contribution to cultural wellbeing and risk management in the context of core institutional operations and obligations.
2. Internal and external interests workshop the issues, related risks, and identify potential indigenous knowledge stewardship accountabilities
a) The potential of issues to emerge as legal or managerial accountabilities;
b) Linking impacts with the activities of the seed bank; and,
c) The potential to demonstrate indigenous knowledge stewardship without disproportionate diversion of resources from main operations.

3. Internal and external interests discuss the accountability concepts to define target priorities a) For performance reporting; and,

b) For action by the seed bank alone or in collaboration with others.

The process of strategic boundary setting and performance management ought to provide seed banks with the ability to place their indigenous knowledge stewardship performance in the context of accountability for cultural wellbeing and risk. This approach provides institutions with capacity to: ${ }^{60}$

1. Identify and meet expectations of knowledge accountability and overcome the reluctance of indigenous communities to share resources and knowledge due to bio piracy concerns;

2. Provide certainty for indigenous people and seed banks about the terms of access and use by documenting the links between genetic resources, knowledge and product use; and track indigenous knowledge exchange throughout;

3. Embed access and benefit sharing as a long-term relationship rather than a one-time access event;

4. Build lasting partnerships that may include accreditation of a trusted institutional collection;

5. Demonstrate accountability for safe handling of knowledge; reduced risk of mismanaged or misused traditional knowledge in institutional collections, and demonstrate competence.

These potential benefits foreshadow the need for performance management systems in conservation seed banks to include indigenous knowledge stewardship accountability. It is important that this is carried out as part of a relationship between institutions and indigenous communities based on a shared vision to minimise the risk to indigenous knowledge wellbeing from seed bank operations.

\section{Conclusion}

This paper identifies the theoretical basis for an approach to strategic management of indigenous knowledge stewardship by seed bank institutions. Such an approach may help increase the capacity of indigenous Australians to manage their knowledge because it is acquired from and transferred through an institutional collections management system, which is important to foster a productive working relationship between seed bank institutions and indigenous Australians. Ensuring indigenous knowledge stewardship in seed banks involves a process for indigenous participation in planning operations at all stages of collections

\footnotetext{
${ }^{60}$ Lockie et al, above n 58.
} 
management, including recognition of indigenous community conservation projects and plans and respect for local indigenous decision making structures, procedures and timeframes.

Such a strategic management process ought to provide seed bank institutions with the ability to place their performance in the context of cultural wellbeing and risk management, and to specify their indigenous knowledge stewardship accountability. It involves genuine engagement between internal and external interests and publically acknowledged boundaries of accountability for indigenous knowledge stewardship. A strategic management process would enable institutional views about accountability to be more closely aligned with improved sensitivity to the cultural wellbeing of indigenous interests and the risks that these pose to seed bank institutional operations. Once such relationships are established with internal and external interests and accountability is clear, there is a basis for ongoing engagement to assist with refining the boundaries of the indigenous knowledge stewardship accountability over time. 